

\begin{tabular}{|c|c|c|c|}
\hline$\Omega$ & [1] & $\equiv$ & (2) \\
\hline Pippa Powell', & 'European Lung Foundation & S. Masefield: European & Sarah.Masefield@europeanlung.org \\
\hline Sarah Masefield', & $\begin{array}{l}{ }^{2} \text { European Lung Foundation } \\
\text { Chair }\end{array}$ & $\begin{array}{l}\text { Lung Foundation, } \\
442 \text { Clossup Road }\end{array}$ & \\
\hline $\begin{array}{l}\text { Lauren Anderson', } \\
\text { Monica Fletcher }{ }^{2}\end{array}$ & & Sheffield, S10 $2 \mathrm{PX}$ & \\
\hline
\end{tabular}

\section{Support Healthy Lungs for Life: holding a spirometry event}

\section{Summary}

The aim of this article is to introduce you to the new European Respiratory Society (ERS)/European Lung Foundation (ELF) initiative "Healthy Lungs for Life", and to provide you with ideas and guidance on ways that you can join in and take part in this exciting campaign. The article will focus on spirometry and how running a testing event in your community can help put lung health at the forefront of public thinking.

\section{Healthy Lungs for Life}

The editorial on page 5 of this edition of Breathe introduces the European Respiratory Society (ERS)/European Lung Foundation (ELF) initiative "Healthy Lungs for Life" and provides details about its aims, scope and activities [1]. As the largest-ever lung health campaign, this global initiative will build on the previous successes of World Spirometry Day (WSD) and extend this awareness day into a full month of events, projects and promotional activities centred on the importance of healthy lungs, with this year's theme that clean air is essential for lung health.

Healthy Lungs for Life 2014 aims to: 1) increase knowledge of the impact of poor air quality on lung health; and 2) raise awareness of the actions that everyone can take to protect their own lungs from indoor and outdoor air pollution. In the long term it seeks to reduce the number of people suffering from respiratory disease by raising awareness and knowledge of lung conditions and ways to prevent lung damage.

\section{How can you get involved?}

We are inviting respiratory professionals from across the globe to join us in this campaign and we can help you by providing resources and materials to host your own events. The more people supporting and taking part in events, the more powerful the messages will be.
Statement of Interest P. Powell, S. Masefield and L. Anderson are employees of ERS. 
Below are some of the activities the ERS is planning for the ERS International Congress 2014 in the host city of Munich as part of the campaign:

- A large-scale public spirometry testing event in the Odeonsplatz on September 5-6, 2014 incorporating facts and statistics relating to lung health

- Patient "meet the expert" evenings organised in conjunction with European patient groups, where specialists in clean air and lung health will present and answer questions from patients and carers

- Kids Clean Air Project, where 4000 children across Munich will take part in a competition on the theme of lung health and clean air, with the winner's work shown in the Congress Opening Ceremony

\section{Public spirometry events}

You can support the Healthy Lungs for Life campaign by holding a spirometry testing event with the theme of clean air and lung health. Spirometry tests are an important tool in diagnosis and condition management, and can help patients understand the impact of indoor and outdoor environments on their lungs.

Previously, WSD events have been held across the globe in 2010 and 2012. In 2012, more than 760 events took place in 70 countries, with 73 spirometry training events held in both low and high income countries [2]. We aim to further improve these figures with the 2014 campaign. The number of events held and people tested will be announced and a report on all participating events will be produced at the end of the campaign.

There are many ways in which you can get involved and recreate the Healthy Lungs for Life events in your own community:

- Sign up for updates on the Healthy Lungs for Life website: www. healthylungsforlife.org

- Follow the campaign on social media (@europeanlung or @ERStalk)

- Visit the ELF/ERS stands at the ERS International Congress and pick up badges and other promotional items

- Display a Healthy Lungs for Life poster in your workplace

- Run a session for patients about the impact of air on lung health

- Hold a public lung function testing event

- Hold an educational spirometry training event for professionals
You are encouraged to hold an event at a time that works for you, in your hospital or surgery, or in a public place (perhaps at a place that you know to have high or low pollution levels), such as a city centre or a park. A new website will be launched for the Healthy Lungs for Life campaign, providing you with all the resources you might need to run an event. You can also look at the WSD2012 official report and reports from event organisers for inspiration [2]. The editorial on the Healthy Lungs for Life campaign, in this edition of Breathe, may also give you some ideas on how to use the clean air theme in your event.

\section{Inspiration}

Events can be organised on a range of budgets and we would encourage you to tailor your event depending on the available resources, the funds you have acquired, and the needs of the public and healthcare professionals in your community or country. Here are some examples of events held in 2012 , to give you an idea of what you could do in 2014 to support Healthy Lungs for Life.

A spirometry training event was held for healthcare professionals in Kathmandu, Nepal. The organisers emphasised the need for spirometry testing to be available to the public, and the importance of learning how to perform the test properly. The event was captured on film so that it can be distributed more widely in Nepal.

The French, Italian and German respiratory societies went all out for WSD 2012. Each society developed their own website and held a series of events across their countries. The Italian Respiratory Society launched their campaign with a press conference hosted at the Italian Senate. The 42 events held throughout the country included public testing events and a mass cycle machine ride in Florence.

The WSD2012 message to "join the race for healthy lungs" inspired many to hold exercise-themed events. The Bulgarian national society held a huge campaign throughout the country, fronted by Olympic gymnast Yordan Yovchev ("Lord of the Rings"), who has competed in six consecutive Olympic Games. They produced a video with the Olympian taking a spirometry test, which was broadcasted nationally on bTV. 
The Portuguese Society of Pulmonology organised a high-profile campaign, which took place in its own mini Olympics site, complete with running track and Olympic torch (fig. 1). A total of 2568 spirometry tests were performed during the campaign, which was supported by Olympic gold medallist, Fernanda Ribeiro and world champion, Aurora Cunha. Information was made available in 300 hospitals and health centres, and interviews with the Portuguese Respiratory Society president, Carlos Cordeiro, were aired on TV.

In Hong Kong, a public event was held at Quarry Bay Community Hall, and opened by Mary Ip (president of the Asian Pacific Society of Respirology) (fig. 2). The event featured educational talks, spirometry tests, doctors, enquiry counters, fencing demonstrations, an educational board and game booths. Five radio programmes, three TV programmes and a local popular newspaper all covered the event. Posters were also displayed in major hospitals and non-governmental organisations.

Students receiving spirometry equipment as part of the American Thoracic Society (ATS) PATS MECOR course in 2011 in Nairobi were encouraged to hold testing events for WSD2012. The response was inspiring, with 18 events held in Nigeria, Benin, Democratic Republic of Congo, South Africa and Cameroon. Most of the events were held in hospitals, clinics and health centres, but there were also events in local markets, shopping centres and at the Comrades Marathon.

Other highlights included a parade for lung health in Bangladesh (fig. 3), lung testing at the home of the modern Olympics, Much Wenlock, in the UK and a WSD2O12 London bus in Blackpool. The WSD2012 official report provides more information about these and other events held around the world [2].

\section{How to run a spirometry event}

\section{How much will it cost to run an event?}

Holding a spirometry event does not need to be expensive. For an event in a doctor's surgery or hospital you will only need basic signage, flyers and posters. Equipment that is already available should be used and controlled by appropriately trained staff, in

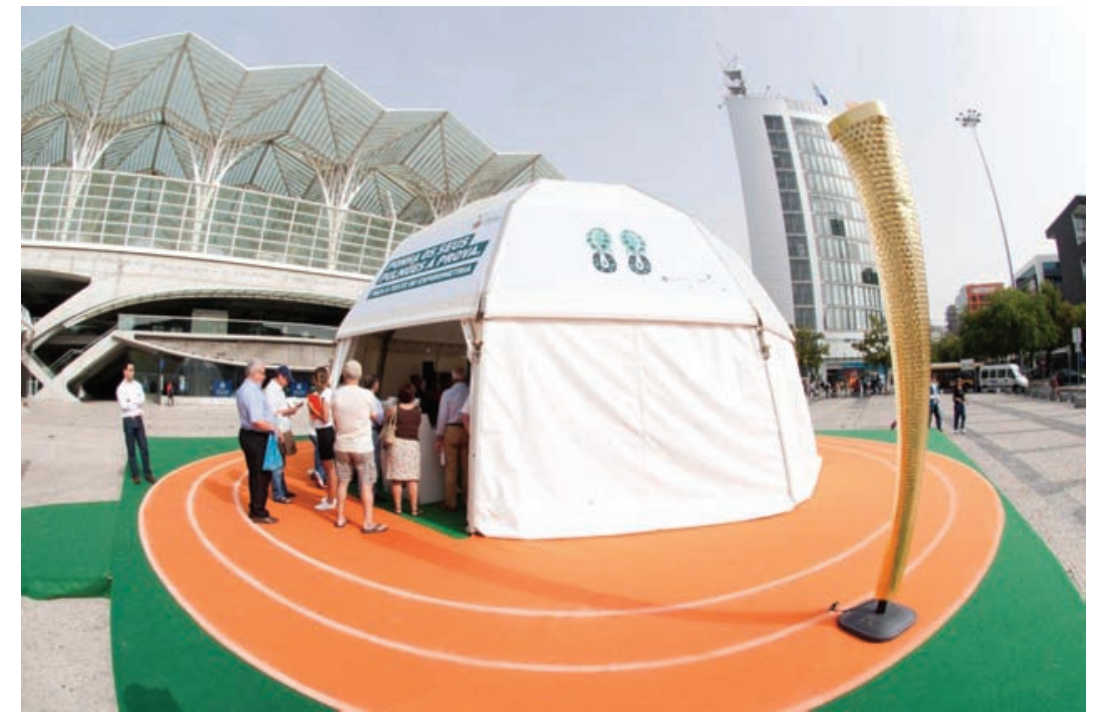

Figure 1

Olympics.

order to ensure that the tests are carried out safely and correctly.

A larger event to reach greater numbers and attract media interest will require more resources and support. A local public relations agency can be used to organise cooperation with local TV and radio as well as running a small press conference if there is enough interest from local journalists.

If you need to seek sponsorship, it is best if this comes in the form of an unrestricted grant from a company with an interest in promoting awareness of lung diseases, lung health and/or clean air. The funds given
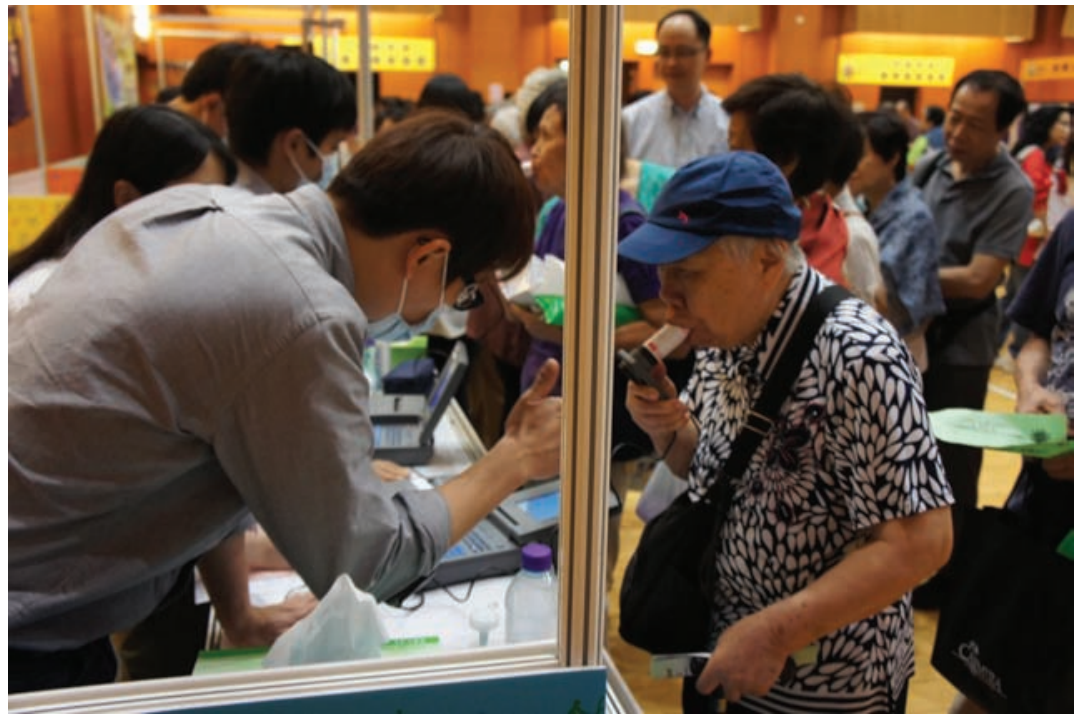

Figure 2

Spirometry. 


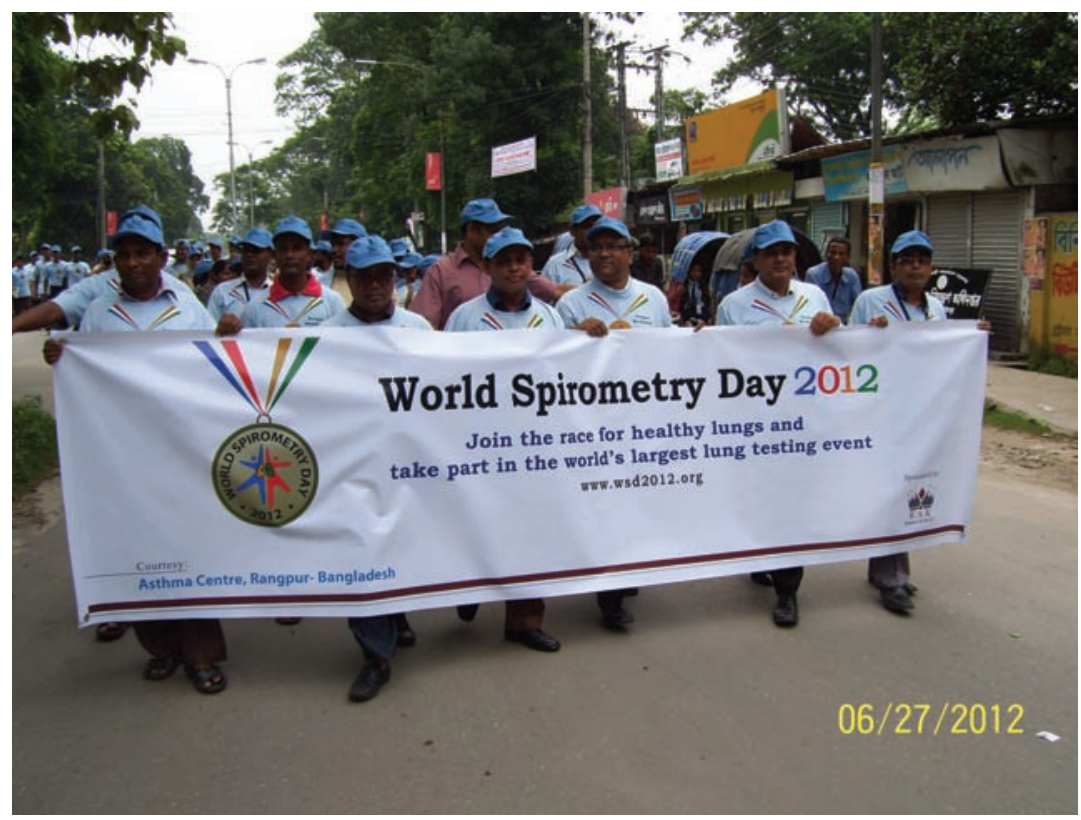

Figure 3

WSD2012.

\section{Who do you need to staff an event?}

You may want to include the following staff in running an event:

- An event organiser: to take control of the logistics and work with the doctors/nurses before and during the event

- A welcome team: to explain the process, hand out questionnaires (if using), organise a queuing system and to distribute leaflets

- Appropriately trained nurses/physiologists/technologists/doctors: to carry out the tests. Remember to ensure that you have enough staff to allow for breaks. Each test should take approximately 10 minutes based on a patient performing three blows

- Doctors: to give immediate advice to those with restricted air flow or those who wish to quit smoking

- Smoking cessation support groups: to advise patients in the waiting area

should hold no restriction on the event and any agreement made with a sponsor should ensure that they have no input into the running of the event.

\section{What do you need to run an event?}

- Spirometers

- Mouth pieces

- Furniture (table and chairs)

- Tissues

- Posters

- Signage

- Name badges for staff

- Questionnaires if using (and pens)

- Letter to refer to family doctor

- Patient information leaflets

- Printers or something to write the results on

- Water and cups

- Waste baskets

You may wish to provide all staff with tshirts and name badges to make them stand out from people coming to have their lungs tested. You can have your own t-shirts made using the examples that will be available on the website. You may also wish to use the letter for doctors that will be available on the website. If someone's lung test result is unusual or irregular you can add their results to this letter and give it to the person to take to their regular doctor.
- Local patient groups: to provide information and raise awareness of the additional support available for patients with lung conditions and their families

\section{A chance to inform the public}

A spirometry event provides a unique opportunity to educate members of the public while they are waiting to have their lungs tested. Therefore, a range of reading material on lung diseases, indoor and outdoor air pollution will be available on the Healthy Lungs for Life website.

Many patient organisations will have relevant material available, as well as staff who can attend the event. A patient information pack with a number of informative materials aimed at patients and produced by the ELF and patient organisations in Europe will be available. You can access a list of patient organisations throughout Europe on the new ELF website to find out if there is a group near you that you could work with on an event (http://www. europeanlung.org/en/get-involved/europeanpatient-organisation-network/).

\section{How should testing be performed?}

- A training session with full guidelines on how to use all spirometers should be 
conducted before the event. Please refer to the standards document: Diagnostic Spirometry in Primary Care [3]. Please also visit the Global Lung Function Initiative website to find out about the new spirometry equations (http://www.lungfunction.org/) [4].

- If using questionnaires there should be a link (identity number) between the questionnaire and the spirometry test.

- Patient safety checks should be made to ensure no contraindications. All spirometry should be performed with the patient sitting down.

- Three acceptable blows (if possible) should be performed by each person in accordance with ERS/ATS Standards 2005 [5]. A printout or written results should be handed to the person and any problems should be explained.

Please make clear to participants that as this is a screening event under non-perfect testing conditions, a diagnosis cannot be definitively given and if they are at all concerned, they should visit their healthcare professional for a full diagnosis.

\section{How to deal with abnormal results and other health issues}

Those showing an abnormal spirometry result (abnormal curves or values) or people who have symptoms and are worried should be given a letter to take to their regular doctor. The letter should be addressed to their doctor to request a confirmation of the findings and to advise further investigation. An example of this letter will be available on the Healthy Lungs for Life website. If children have abnormal values, letters for their doctor should be given to the child in the presence of their parent/ guardian.

People should also be given the opportunity to speak to a doctor onsite. If someone is a smoker and concerned about their lung health, introduce them to a smoking cessation expert or give them contact details for a local smoking cessation group.

\section{How to promote an event}

Any promotional activities should focus on promoting the event to local residents to encourage them to attend. Some examples of effective activities include:

- Contacting local press, radio and TV in advance, and providing information on the event itself and also on the impact of poor air quality on lung health

- Sending promotional posters and flyers to nearby doctors surgeries and making them available in waiting areas

- Advertising your event in local free newspapers and online listings

- Holding a small press conference at the opening of your event where journalists can test their lungs (dependant on the level of local interest that your event has generated)

Examples of all the above materials will be available in the press pack on the Healthy Lungs for Life website.

\section{Ethical issues}

Depending on the rules in each country, approval from the regional/national medical ethics committee may be needed before the event takes place. In some countries, approval may also be needed from national data authorities if the results are going to be stored. In some countries, staff may need to ensure that they have additional liability cover to perform spirometry outside the hospital environment. It is up to organisers and participating staff to find this out as soon as possible to avoid cancellation or undue risk to their jobs at these events.

\section{Practical tips}

- Staff at the event should be advised to leave bags in a safe place and avoid bringing coats and personal belongings, if at all possible

- Encourage everyone to arrive in good time

- The event organiser should be informed of the arrival of all staff to ensure appropriate people are running each area

- Staff should be advised to wear or pick up specific clothing (if used) and pick up a name/title badge

- A water cooler and cups should be made available for patients and staff. All staff should be told where the water is and who to speak to if the water runs out

- Directions to the nearest toilet should be given

- Details on food provided (if any) should be given

- Information should be provided on what to do if someone is taken ill 
The Healthy Lungs for Life website will be live from March 2014 (www.healthylungsforlife. org), where all the information about the campaign and for World Spirometry Day 2014 will be available, including all the materials mentioned above, and more.

If you have any questions or would like more information, before the website is live, email sarah.masefield@europeanlung.org

\section{References}

1. Eickelberg O, Fletcher M, Barnes P. Healthy lungs for life campaign: a festival of lung health for the ERS International Congress, Munich and the globe. Breathe 2014; 10: 5-7.

2. World Spirometry Day 2012. Spirometry report. www. wsd2012.european-lung-foundation.org/17908-wsdresults.htm

3. Levy ML, Quanjer PH, Booker R, et al. Diagnostic Spirometry in Primary Care. Proposed standards for general practice compliant with American
Thoracic Society and European Respiratory Society recommendations. Prim Care Respir J 2009;

18: 130-147.

4. Stanojevic S, Quanjer P, Miller MR, et al. The Global Lung Function Initiative: dispelling some myths of lung function test interpretation. Breathe 2013; 9: 462-474.

5. Miller MR, Hankinson J, Brusasco V, et al. Standardisation of spirometry. Eur Respir J 2005; 26: 319-338. 